\title{
La forma de selección del Tribunal Constitucional canadiense. Una posible guía para el debate constituyente chileno
}

\author{
The form of selection of the Canadian Constitutional \\ Court. A possible guide to the Chilean Constituent \\ debate
}

Daniel Fernández Cañueto ${ }^{1}$

Universitat de Lleida

daniel@dpub.udl.cat

\begin{abstract}
Resumen: El texto tiene por finalidad espolear el debate en relación al nombramiento de los magistrados, el procedimiento y los criterios de selección del Tribunal Constitucional chileno a la luz de una experiencia extranjera que creemos interesante teniendo en cuenta el contenido de los debates relativos a la nueva Constitución que se están generando en el interior del país. Para llevar a cabo nuestra tarea, hemos dividido el artículo en dos apartados. Un primero, y siquiera el más extenso, donde se analizarán las novedades en relación al nombramiento de los magistrados, el
\end{abstract}

1 Doctor en Derecho Constitucional por la Universidad de Barcelona y actualmente profesor de la Universitat de Lleida en calidad de investigador postdoctoral. Sus líneas de investigación principales son la democracia constitucional, la representación política y el federalismo. Asimismo, es co-fundador del Seminario "Nuevos Horizontes del Derecho Constitucional" para jóvenes doctorandos. 
procedimiento y los criterios de selección de la Corte Suprema de Canadá, haciendo además un breve repaso a su historia y sus problemáticas esenciales para obtener una mejor comprensión del contexto en el que se han fraguado dichas innovaciones. Y, por último, un segundo apartado, que además coincidirá con las conclusiones, en el que trataremos de exponer la utilidad del caso canadiense para el actual debate constitucional chileno.

Palabras clave: Tribunal Constitucional chileno, Corte Suprema de Canadá, nombramiento, procedimiento y selección.

Abstract: The purpose of the text is to spur debate on the appointment of magistrates, the procedure and the selection criteria of the Chilean Constitutional Court in the light of a foreign experience that we believe is interesting considering the content of the debates regarding the Constitution that They are being generated inside the country. To carry out our task, we have divided the article into two sections. A first, and even the most extensive, where the novelties regarding the appointment of magistrates, the procedure and the selection criteria of the Supreme Court of Canada will be analyzed, also briefly reviewing its history and its essential problems to obtain a better understanding of the context in which these innovations have been forged. And, finally, a second section, which will also coincide with the conclusions, in which we will try to explain the usefulness of the Canadian case for the current Chilean constitutional debate.

Keywords: Chilean Constitutional Court, Supreme Court of Canada, appointment, procedure and selection.

\section{Introducción}

Después de que las reformas constitucionales (1989, 1991, 1994, 1997, 1999, 2000, 2001, 2003, 2005, 2007, 2008, 2009, 2010, 2011, 2012, 2013, 2014, 2015 y 2017) hayan sido consideradas por muchos como insuficientes para transitar de una Constitución otorgada en 1980 por Pinochet a una Carta Magna que permita desarrollar con profusión los principios del Estado democrático y social de Derecho, Chile parece estar inmerso en un doble debate: de qué manera se configura el proce- 
so constituyente que dé lugar a una nueva Carta Magna y, por el otro, especificar en qué dirección debe ir la reforma constitucional o cuál debe ser el contenido de la futura Constitución. En el seno de esta segunda polémica, pues la primera ya va siendo contestada mientras se escriben estas líneas, se encuentran tanto las críticas como las propuestas de modificación relativas al Tribunal Constitucional chileno². Sobre esto último, el Informe final del Grupo de Estudio de Reforma al Tribunal Constitucional realizado el 28 de junio de $2019^{3}$ recuerda que actualmente existen 19 proyectos de reforma constitucional sobre el máximo intérprete de la Carta Magna en el interior del Congreso Nacional, versando quince de ellos sobre su jurisdicción o su funcionamiento interno y cuatro sobre su forma de nombramiento, procedimiento y criterios de selección (Boletines N ${ }^{\circ} 11.680-07,11.663-07,10.193-07$ y 11.617-07). Siendo únicamente el presentado por el Frente Amplio (Boletín N011.680-07) y el introducido por la expresidenta Bachelet en su proyecto de reforma constitucional (Boletín $\left.\mathrm{N}^{0} 11.617-07\right)$ los que proponen cambios sustanciales sobre dichos aspectos ${ }^{4}$.

Ahora bien, y por contradictorio que parezca, no tenemos por objetivo realizar un análisis crítico de las fórmulas actualmente vigente en Chile, ni mucho menos acabar elaborando específicas propuestas de modificación. Más bien al contrario, el texto que ahora se inicia tiene por finalidad espolear el debate en relación al nombramiento de los magistrados, el procedimiento y los criterios de selección del Tribunal Constitucional chileno a la luz de una experiencia extranjera que creemos interesante teniendo en cuenta el contenido de los debates relativos a la nueva

2 Un ejemplo de dichas críticas puede encontrarse en los siguientes textos: BASSA (2015), pp. 253-283; LibEDINSKY (2003); RÍOS (2002), pp. 203-206; SieRRA (2015); VIERA (2015); SieRRA (2016); Couso (2010), pp. 191-216. Asimismo, un magnífico resumen sobre las propuestas de reforma que actualmente están en el Congreso Nacional en relación al Tribunal Constitucional chileno se puede leerse en el Informe final del Grupo de Estudio de Reforma al Tribunal Constitucional. 4 propuestas para un Tribunal Constitucional del Siglo XXI, Santiago de Chile, 2019.

3 Informe que se hizo público en el auditorio del CEP el 9 de septiembre de 2019.

4 Para realizar tales afirmaciones, dicho documentos se apoya en un informe publicado por la Biblioteca del Congreso Nacional en octubre de 2018 y elaborado por la Comisión de Constitución, Legislación, Justicia y Reglamento de la Cámara de Diputados que lleva por título: Comparación de Proyectos de Reforma al Tribunal Constitucional, Nº SUP: 117106. 
Constitución que se están generando actualmente en el interior de Chile.

Para llevar a cabo dicha tarea, hemos creído conveniente dividir el artículo en dos apartados. Un primero, y siquiera el más extenso, donde se analizarán las novedades en relación al nombramiento de los magistrados, el procedimiento y los criterios de selección de la Corte Suprema de Canadá, haciendo además un breve repaso a su historia y sus problemáticas esenciales para obtener una mejor comprensión del contexto en el que se han fraguado dichas innovaciones. $Y$, por último, un segundo apartado, que además coincidirá con las conclusiones, en la que trataremos de exponer la utilidad del caso canadiense para el actual debate constitucional chileno.

\section{La Corte Suprema de Canadá}

\subsection{Evolución histórica}

La vida de la Corte Suprema canadiense ha estado marcada por cuatro grandes periodos que se corresponden con la importancia que esta institución ha tenido en el interior de la Federación a lo largo de la historia, pues de no existir entre 1867-1875 y ser accesoria entre 1875-1949, pasó a convertirse en la última Corte de Apelación en 1949 y omnipotente en 1982.

\subsubsection{Primera etapa: inexistencia (1867-1875)}

Para todos los países que formaban parte del Imperio británico, entre los cuales se incluía Canadá, la última Corte de Apelación era el Judicial Committee of the Privy Council (en adelante JCPC), un tribunal al que podían acudir en última instancia todos los súbditos/territorios de la monarquía británica y que estaba parcialmente formado por miembros de la House of Lords ${ }^{5}$. Los padres fundadores canadienses tuvieron muy claro que ese estatus colonial limitaba la discrecionalidad de los países miembros del Imperio británico a la hora de concebir la cúspide de sus judica-

5 Actualmente muchas de las antiguas colonias del Reino Unido todavía siguen vinculadas a la Corona británica a través de la Commonwealth of Nations. 
turas, de modo que diseñaron en base a ello la forma que podría tener su sistema judicial interno. En la Constitucion Act de 1867 (en adelante CA de 1867) se estableció un art. 101 que únicamente permitía al Parlamento de Canadá crear una Corte General de Apelación para todo el país, es decir, sólo posibilitaba que el poder legislativo diseñara una Corte que fuera una institución intermedia entre los Tribunales Superiores de cada una de las Provincias y el JCPC radicado en Londres ${ }^{6}$.

Así pues, si bien la CA de 1867 ni estableció una Corte Suprema ni determinó cual debía ser la cúspide judicial interna de Canadá, sí que habilitó al legislador ordinario para que, a través del art. 101 y si lo consideraba oportuno, creara y configurara un Tribunal de Apelación que fuera general para Canadá, pero intermedio en el marco de la estructura judicial del Imperio británico.

\subsubsection{Segunda etapa: accesoriedad (1875-1949)}

Durante la década posterior a la entrada en vigor de la CA de 1867, tanto los políticos conservadores como los liberales coincidieron en la necesidad de desarrollar el art. 101 para que Canadá tuviera una Corte Suprema que abarcara jurisdiccionalmente a toda la Federación ${ }^{7}$. Si bien determinadas controversias políticas hicieron que los dos primeros intentos de regulación fallaran ${ }^{8}$, en 1875 se acabó aprobando la Supreme Court Act, una ley ordinaria que no sólo creaba dicho tribunal, sino que también regulaba su jurisdicción, la forma de nombramiento de sus magistrados, los criterios de selección, la composición y su funcionamiento interno ${ }^{9}$.

Por lo que respecta a la jurisdicción, dicha ley estableció que la Corte Suprema podía recibir tanto recursos sobre normas constitucionales o

6 Woehrling (2006) p. 126; Pelletier (2016), pp. 41-42.

7 SNell y Vaughan (1985), pp. 3-4.

8 El 21 de mayo de 1869 y el 18 de marzo de 1870 se pasaron sendas propuestas de ley para crear la Corte Suprema que no fueron aprobadas por el Parlamento. Para un mayor conocimiento de ambas propuestas de ley fallidas y el debate en relación a la Supreme Court Act véase: HERMAN (1976), pp. 7-10.

9 Aiello (2013), pp. 277; Bilodeau (2010), pp. 423.-424. 
federales como apelaciones que provinieran de los tribunales provinciales sobre cuestiones provinciales. En cuanto a la forma de nombramiento de los magistrados, la Supreme Court Act reprodujo el patrón británico al otorgar un poder ilimitado al Ejecutivo, es decir, estableció en el art. 4(2) que los jueces debían ser nombrados por "the Governor in Council", lo que literalmente significaba escogidos por el Gabinete junto al Gobernador General pero que, en la práctica jurídico-política canadiense, supuso que tanto el Primer Ministro como el Ministro de Justicia fueran quienes decidieran qué magistrados se nombraban ${ }^{10}$. En relación a los criterios de selección de los jueces, el art. 5 de dicha ley fijó que éstos debían ser escogidos de entre quienes fueran/hubieran sido jueces de la Corte Superior de la Provincia o abogados con 10 años de pertenencia al Colegio de Abogados provincial ${ }^{11}$. Por último, en cuanto a su composición, la Supreme Court Act determinó que dicho tribunal estaría integrado por seis magistrados, de los cuales dos debían provenir obligatoriamente de Quebec $^{12}$. Imperativo legal este último al que, ya en su concepción y en base a los principios del federalismo, le iría aparejado el consenso político de que el resto de asientos debían repartirse en base a la importancia que tuviera cada provincia y/o región en el interior de Canadá ${ }^{13}$. Cuestión por la cual, mientras en los primeros compases se otorgaron dos a Ontario, otros dos a las provincias marítimas y ninguno a las del Oeste (que todavía no existían como tales), en 1903 uno de los asientos adjudicados a las provincias marítimas pasó a ser de las recién creada provincia del Oeste gracias a la Ley de fronteras de Ontario en $1889^{14}$.

Una vez promulgada la ley, la Corte Suprema fue inaugurada en una cena de estado el 18 de noviembre de 1875, escuchó su primer caso en abril de 1876 y comenzó a celebrar sesiones ordinarias en 1877. Desde

10 LeIth (2009), p. 14; Russell (2017), p. 5.

11 McWhinney (1986), p. 65; Hogg (2013), p. 14.

12 Además del Presidente del Tribunal Supremo Richards, los jueces originales fueron William Johnstone Ritchie, Samuel Henry Strong, Jean-Thomas Taschereau, Télesphore Fournier y WiIliam Alexander Henry.

13 Asimismo, una de las pocas veces que dicho patrón provincial no fue seguido sería en la nominación realizada por John A. MacDonald en 1888; Cf. SNELL y VAUGHAN (1985), p. 159.

14 SNeLl y VAughan (1985), pp. 12 y 159. 
ese momento y hasta 1949, tres serían los principales hechos que harían aumentar la importancia de la Corte Suprema en el interior de la estructura judicial del Imperio británico, para el moderno patriotismo canadiense y para conseguir una mejor integración de la Federación. Lo primero se daría en 1883, pues al declarar el JCPC que sólo se podía apelar a él sobre casos cuya cuantía fuera sustancial o de grave interés público-legal, hizo que la Corte Suprema canadiense se convirtiera en el último tribunal de apelación para los casos menores ${ }^{15}$. Lo segundo se daría en 1926, pues el Presidente de la Corte Suprema envió un memorándum al Primer Ministro afirmando que, como cualquier otra nación independiente, debía tenerse la última Corte de Apelación en suelo canadiense. Y lo tercero se realizaría fruto de la modificación de la Supreme Court Act que se llevó a cabo en 1927, pues, aparte de establecer la edad de jubilación a los 75 años para los magistrados, aumentó el número de jueces a 7 , cuestión que permitió tanto una mejor distribución de los asientos en base a la importancia que tenían en ese momento cada una de las regiones ${ }^{16}$ como una mayor celeridad a la hora de resolver los $\operatorname{casos}^{17}$.

Ahora bien, aunque la promulgación de la Supreme Court Act en 1875 permitió sentar las bases de una institución que podía estar llamada a ser el último tribunal de apelación canadiense, y algunos hechos ulteriores favorecieron esa deriva, ello no significó que la Corte Suprema dejara de tener carácter intermedio y secundario. $Y$ eso fue así por tres razones. Uno, porque ésta no dejó de estar obligada a seguir los precedentes sentados por el JCPC, de manera que no podía desarrollar una jurisprudencia o técnica judicial propia. Dos, porque sus sentencias todavía podían apelarse ante el JCPC Y tres, porque se podía acudir al tribunal londinense sin que hubiera existido un pronunciamiento previo de la Corte Suprema, cuestión que sucedió en 77 de los 159 casos que llegaron al JCPC en relación a la constitución canadiense durante esa época ${ }^{18}$.

15 Aiello (2013), pp. 278-286.

16 Ganar un segundo asiento era el reconocimiento velado del aumento de la importancia a nivel económico que tenían las provincias del Oeste en el seno de la Federación canadiense.

17 SNell y VAughan (1985), p. 159.

18 Russell, Knopff y Bateman (2008), p. 4; Snell y Vaughan (1985), p. 42; Herman (1976), p. 13; 


\subsubsection{Tercera etapa: última Corte de Apelación (1949-...)}

La consolidación de aquel patriotismo canadiense que había ido surgiendo durante las tres primeras décadas del siglo $\mathrm{XX}$ comportó que la posibilidad de apelar al JCPC se viera cada vez más como un símbolo de inferioridad colonial. Argumento político éste al que se le añadieron otros más técnicos como fueron que el JCPC estaba empezando a distorsionar el equilibrio de poderes establecido en la CA de 1687 a favor de las provincias o que dicho tribunal londinense se había convertido en un freno para que la división de poderes constitucionalmente establecida pudiera adaptarse a las necesidades de un Canadá que salía de una guerra mundial y se enfrentaba a la gran depresión ${ }^{19}$.

Todas estas críticas, junto a la aprobación del Estatuto de Westminster en 1931 donde se otorgó plena autonomía legislativa a los países miembros del Imperio británico (de manera que parecían eliminarse los obstáculos legales para que el Parlamento canadiense pudiera suprimir todas las apelaciones al JCPC) ${ }^{20}$, hicieron que durante los siguientes tres lustros tratara de avanzarse en convertir a esa Corte Suprema secundaria en la última instancia de apelación de la Federación. En relación a ello, en 1933 se aprobó una ley mediante la cual el JCPC ya no sería la última Corte de Apelación en cuestiones criminales ${ }^{21}$. Entre 1938-1939, y aunque ninguna de ellas acabó prosperando, se introdujeron diversas propuestas que tuvieron como objetivo eliminar todas las apelaciones al Privy Council. En 1940, a través de una opinión consultiva sobre una de las anteriores propuestas ${ }^{22}$, la Corte Suprema acabó declarando que, fru-

LeITH (2009), p. 13.

19 Dichas críticas se empezaron a realizar después que el JCPC invalidara una parte de la legislación que el Gobierno canadiense había promulgado con el objetivo de hacer frente a la gran depresión que estaba socavando los cimientos de dicha comunidad política. Cf. MACDONALD (1951), pp. 1021-1037; HeRman (1976), pp. 23-26.

20 RUSSELL (1969), p. 33.

21 En 1888, gracias al Ministro de Justicia John Thompson, se había aprobado una ley similar, pero en 1926 el JCPC declaró que ésta no podía ser aplicada dado que el Parlamento canadiense no tenía jurisdicción más allá de Canadá (famoso caso Rex vs Nadal). Cf. Pelletier (2016), pp. 53-54.

22 Reference as to the Legislative Competence of the Parliament of Canada to Enact Bill No. 9 of the Fourth Session, Eighteenth Parliament of Canada, entitled "An Act to Amend the Supreme 
to de la aprobación del Estatuto de Westminster en 1931, el Parlamento canadiense tenía potestad para eliminar las apelaciones al JCPC. Y, por último, en 1947 el propio JCPC reafirmó la postura mantenida siete años antes por la Corte Suprema de Canadá23.

Asimismo, los avances que permitían convertir a la Corte Suprema en la última Corte de Apelación canadiense se alternaron con los recelos de algunas provincias, pues, según éstas, de conseguirse dicho objetivo podría modificarse el equilibrio de poderes a favor del Gobierno federal por tres motivos concatenados: porque los miembros de la Corte Suprema seguirían siendo elegidos por el Gabinete, porque pasaría dicho tribunal a jugar un papel decisivo por definitivo en el reparto competencial y porque la Corte Suprema podría desmarcarse de unos precedentes judiciales fijados por el JCPC que históricamente se habían mostrado muy favorable a los intereses provinciales ${ }^{24}$. Es decir, y expresado de forma sucinta, las provincias frenaron políticamente los avances para convertir a la Corte Suprema en la última Corte de Apelación canadiense porque tenían miedo a que, al tener el Ejecutivo el control absoluto sobre el nombramiento de los magistrados, dicho tribunal fuera estructuralmente tendente a beneficiar al Gobierno de la Federación en las cuestiones relativas al reparto competencial.

Esta oposición provincial a eliminar las apelaciones al JCPC fue, en buena medida, la razón por la cual no sería hasta 1949 que el Parlamento pudo aprobar una batería de reformas que convirtieron a la Corte Suprema en la última instancia de apelación canadiense ${ }^{25}$. De todas ellas, las más importantes fueron la anulación de la posibilidad de apelar al JCPC después de que la Corte Suprema hubiera dictado sentencia, la modificación de la jurisdicción de dicho tribunal para que conociera incluso de aquellos procesos sobre los que anteriormente tenía competencia exclusiva el JCPC y, por último, la ampliación del número de magistrados

Court Act", [1940] S.C.R. 49 (Date: 1940-01-19).

23 Pelletier (2016), pp. 55-56.

24 Ruíz (1990), pp. 201-215; Woehrling (2006), p. 128; Castellà (2014), p. 269.

25 Herman (1976), pp. 29-31; Aiello (2013), p. 287. 
de la Corte Suprema a 9, estableciéndose además la obligatoriedad que 3 provinieran de Quebec para garantizar en su seno el conocimiento del derecho civil de la provincia (léase también derecho continental). Imperativo legal este último que también llevaba aparejado el consenso político de que de los otros 6 magistrados, 3 debían provenir de Ontario, 2 de las provincias del Oeste ${ }^{26}$ y 1 de las marítimas ${ }^{27}$. Convención que ha permanecido invariable hasta el día de hoy salvo en una ocasión ${ }^{28}$.

\subsubsection{Cuarta etapa: un tribunal todopoderoso (1982-...)}

Si bien desde 1949 la Corte Suprema era la última institución a la cual se podía apelar en Canadá, existían dos cuestiones relacionadas con dicho tribunal que preocupaban de manera esencial a algunos políticos y académicos: nos referimos a su desprotección frente a la ley ordinaria y a sus limitaciones en cuanto al control de constitucionalidad. Por lo que respecta a la primera, entre 1949 y 1950, la Barristers' Society of New Brunswick, la Law Society of British Columbia y el Tremblay Report trataron, sin éxito, que se modificara el Art. 101 de la CA de 1867 con el objetivo de constitucionalizar a la Corte Suprema, pues al derivar dicho tribunal de una ley ordinaria (la Supreme Court Act), la institución estaba completamente al albur de los deseos de las mayorías parlamentarias coyunturales $^{29}$. En cambio, por lo que respecta a la segunda preocupación, el control de constitucionalidad que dicho tribunal venía realizando se limitaba a la distribución de competencias legislativas entre los dos órdenes de gobierno, no teniendo la posibilidad de analizar el contenido de las leyes. Para tratar de solventarlo, en 1960 se promulgó la Canadian Bill of Rights, una carta de derechos que podía comportar una alteración del control de constitucionalidad que la Corte ejercía, pues, en teoría,

\footnotetext{
26 De los dos asientos asignados a las provincias del Oeste, también existe la convención que uno está reservado para British Columbia, mientras que el otro es rotativo entre Alberta, Manitoba y Saskatchewan.

27 Woerhling (2006), pp. 194-195; Sossin (2013), pp. 41-42.

28 La excepción a la norma se dio en 1979 cuando, con el consentimiento de la primera, la vacante del juez de Ontario Wishart Spence fue rellenada por William Mclntyre de British Columbia. Cf. RusSell (2017), p. 14.

29 Kwavnik (1973); HeRman (1976), pp. 29-31; Aiello (2013), p. 287.
} 
sería posible cuestionar el contenido de la legislación federal. Ahora bien, como dicha Carta de Derechos no se insertaba en la CA de 1867 sino que era una ley federal que únicamente prevalecía frente a otras leyes federales relativas a derechos, la Corte Suprema fue muy reticente a la hora de aplicarla. De hecho, entre 1960 y 1982 sólo invalidó una ley federal por entrar en conflicto con la Canadian Bill of Rights ${ }^{30}$.

Tendrían los canadienses que esperar dos décadas más para que ambas cuestiones fueran solucionadas. No sería hasta la entrada en vigor de la Constitutional Act de 1982 (en adelante CA de 1982) que se daría rango constitucional tanto a un catálogo de derechos y libertades como al procedimiento de reforma constitucional, convirtiendo a la Corte Suprema en una institución fuertemente protegida y jurisdiccionalmente omnipotente. Por lo que respecta a lo primero, la CA de 1982 fijó en su art. 41(d) que la modificación de la composición de la Corte Suprema debía realizarse a través del procedimiento de reforma constitucional agravado (unanimidad de provincias y federación), mientras que su art. 42(1) estableció que la alteración de sus otros elementos esenciales debía realizarse a través del procedimiento ordinario de 7/50 (es decir, al menos siete provincias que representen al $50 \%$ de la población) ${ }^{31}$. A partir de entonces, tanto las características básicas de la institución como su propia existencia gozarían de una mayor protección al no poder ser modificadas mediante el procedimiento legislativo ordinario. Asimismo, en cuanto a la omnipotencia jurisdiccional, la inclusión en la CA de 1982 tanto de un catálogo de derechos y libertades como de un Art. 52(1) donde se afirmaba que no podían existir leyes que fueran incompatibles con las disposiciones constitucionales, supuso que la Corte Suprema pudiera revisar el contenido de cualquier legislación federal o provincial, de manera que

30 Nos referimos al caso Queen vs Drybones en 1969. Cf. MACFARLANe (2009), p. 67.

31 Sobre dicha cuestión, si bien algunos académicos, entre ellos Peter Hogg, han sugerido que las referencias a la Corte Suprema de Canadá en las secciones 41 y 42 de la Constitución de 1982 no tienen eficacia hasta que el Parlamento no añada la Ley del Tribunal Supremo a la lista del artículo 52(2). Y otros académicos, incluyendo al Profesor Cheffins, han argumentado que la Ley del Tribunal Supremo está implícita en el artículo 52(2) debido a que dicha disposición no contiene una lista exhaustiva. La propia Corte Suprema confirmó que forma parte del entramado constitucional en la Reference re Supreme Court Act de 2014. Cf. Russell (1987), p. 67. 
su capacidad de incidir sobre la realidad política y social aumentó exponencialmente ${ }^{32}$. Es decir, y como magníficamente afirma José Woerhling, en Canadá

"El control judicial de constitucionalidad ha conocido una extensión significativa con la adopción de la Carta Canadiense de Derechos y Libertades de 1982 [...] En efecto, cuando el control de constitucionalidad se limita a la distribución de competencias legislativas entre los dos órdenes de gobierno, como era esencialmente el caso en Canadá antes de 1982, los tribunales sólo pueden verificar qué órgano legislativo, federal o provincial, es competente para adoptar una ley en particular; pero no les autoriza para pronunciarse sobre la razón de ser o la oportunidad de la legislación adoptada por ese Parlamento. Al contrario, cuando la Constitución contiene disposiciones que garantizan los derechos y las libertades, los tribunales deben interpretar los términos generalmente indeterminados y abstractos, lo que les lleva inevitablemente a controlar las elecciones sociales adoptadas por los representantes políticos"33

En definitiva, lo antedicho comportó que el sistema canadiense transitara en 1982 de sus raíces británicas de soberanía parlamentaria a otro parcialmente basado en la supremacía constitucional, pues, a partir de ese momento, no existían parcelas de la realidad social que pudieran ser reguladas de manera ilimitada por los detentadores del poder político a través del procedimiento legislativo ordinario ${ }^{34}$. En base a ello, no parece exagerado manifestar que la promulgación de la CA de 1982 fue uno de los acontecimientos más significativos en la historia de la Corte Suprema de Canadá, no sólo porque le otorgó un mayor poder al permitirle entrar a valorar el contenido de toda la legislación canadiense, sino también porque le posibilitó hacerlo con la seguridad de que su estructura esencial únicamente podría ser alterada a través del procedimiento de reforma constitucional $^{35}$.

32 LEITH (2009), p. 32.

33 WOERHLING (2006), p. 227.

34 Cotler (2008), p. 132; Neudorf (2017), pp. 16-17.

35 Russell (1986), p. 194; Pelletier (2016), p. 60. 


\subsection{Forma de nombramiento, procedimiento y criterios de la Corte Suprema canadiense}

En el interior de estas cuatro etapas de la historia de la Corte Suprema que acabamos de examinar, se han ido sucediendo, como mínimo, tres grandes problemáticas. Nos referimos a sobre qué cuestiones puede decidir la Corte Suprema (jurisdicción), quién tiene el poder para designar a los magistrados (nombramientos) y, por último, cómo se realiza el procedimiento y cuáles son los criterios de selección de dichos jueces. De todas ellas, únicamente pasaremos a analizar las dos últimas, pues la primera queda fuera de los objetivos del presente artículo.

\subsubsection{El debate sobre quien nombra a los magistrados}

Dicha gran problemática se desarrolló, de manera esencial, entre 1949 y 1992. Como ya afirmamos anteriormente, la Supreme Court Act otorgó en 1875 un poder casi ilimitado al Ejecutivo en relación al nombramiento de los magistrados, pues en su art. 4(2) estableció que los jueces de la Corte Suprema debían ser nombrados por "the Governor in Council", lo que literalmente significaba escogidos por el Gabinete junto al Gobernador General pero que, en la práctica jurídico-política canadiense, suponía que el Primer Ministro y el Ministro de Justicia eran quienes decidían qué magistrados nombrar ${ }^{36}$. Una discrecionalidad que estaba limitada legalmente por la obligación de que una parte de los jueces provinieran de Quebec ${ }^{37}$ y "restringida" políticamente por la convención de que los demás magistrados debían ser escogidos siguiendo un determinado patrón provincial $^{38}$.

36 Leith (2009), p. 14; Russell (2017), p. 5.

37 Como ya hemos explicitado con anterioridad, mientras hasta 1949 fueron dos los magistrados que debían provenir de Quebec, a partir de ese momento serían tres de los nueve jueces los que era obligatorio que procedieran de dicha provincia.

38 Se ha entrecomillado la palabra restringida porque no estamos hablando de una verdadera limitación legal, pues en la Resolution to Amend the Constitution de 1981, la Corte Suprema aseveró que los tribunales podían identificar la existencia de convenciones pero que no podían imponer su cumplimiento. De esa forma, las sanciones por el incumplimiento de una convención únicamente podías ser políticas. Cf. Re: Resolution to amend the Constitution, [1981] 1 S.C.R. 753. 
Sobre esta realidad jurídico-política no hubo apenas controversia hasta que la Corte Suprema se convirtió en la última Corte de Apelación canadiense en 1949. Al erigirse ésta en vértice del sistema judicial de la Federación y pasar a ostentar un gran poder al dirimir en último lugar cuestiones relativas a la distribución de competencias, tanto desde el ámbito académico como desde el poder político provincial no sólo empezaron a prestarle mayor atención, sino que también comenzaron a examinarla en base a los principios del federalismo. Esa nueva perspectiva analítica acabó articulando un discurso donde se afirmaba que nombrar a los jueces de la Corte Suprema de manera unilateral por el Gobierno federal impedía que dicho tribunal se presentara de forma creíble como una instancia imparcial en los litigios que oponían a los dos niveles de gobierno, pues existiría siempre la sospecha de falta de neutralidad cuando se dictaran sentencias relativas al reparto competencial. Argumento principal éste cuyo epílogo era, en términos generales, que si en los estados federales las instituciones que afectan a los dos niveles de gobiernos debían estar escogidas por ambos, era perentorio tratar de adaptar el nombramiento de los magistrados de la Corte Suprema a esos principios del federalismo ${ }^{39}$.

Aunque ya en 1949 y 1950 hubo pronunciamientos en tal sentido ${ }^{40}$, no sería hasta mediados de los años 60 que, junto al avance del nacionalismo quebequés y tras unas sentencias controvertidas emitidas por la Corte Suprema que afectaban al reparto competencial, desde el poder político provincial se alzara la voz ante lo que se consideraba un Estado excesivamente centralista ${ }^{41}$. Dicho creciente malestar en relación al

39 PeAch (2005), p. 2; Schertzer (2016), pp. 544-545.

40 Durante los debates sobre las reformas que en 1949 acabaron otorgando a la Corte Suprema su nuevo estatus en el entramado institucional canadiense, el conservador Lon Balcer criticó que el nombramiento de sus magistrados se hiciera unilateralmente por el Gobierno Federal y el quebequés Wilfred La Croix propuso en vano que 4 de los 9 jueces fueran escogidos directamente por las provincias. Asimismo, un año después (1950), desde Quebec, y a través del Tremblay Report, se trató de impulsar de manera infructuosa una campaña para que las provincias tuvieran una mayor influencia en los nombramientos de la Corte Suprema. Cf. RusseLL (2017), p. 4; KWAVNIK (1973).

41 CRAndall (2013), p. 81. 
equilibrio de poderes existente en el seno de las principales instituciones canadienses tuvo dos consecuencias: que a nivel estatal se iniciara un periodo de "mega Constitutional politics"42 en el que se quería reformar la arquitectura constitucional en base a los principios del federalismo y que, en relación a la Corte Suprema, la cuestión se centrara en determinar quién debía ostentar legalmente el poder para nombrar a los magistrados.

Sobre esto último, en la Victoria Constitutional Conference de 1971 se pactó que en una eventual reforma debería incluirse un escrutinio provincial de los nombramientos realizados por el Ejecutivo federal ${ }^{43}$. En 1987, el Primer Ministro Brian Mulroney afirmó que debía permitirse la participación de las provincias en el proceso de nombramiento de los jueces de la Corte Suprema porque ello otorgaría mayor representatividad y legitimidad al tribunal, convirtiéndolo en un verdadero vehículo del federalismo intra-estatal al permitir la intervención provincial en una institución federal ${ }^{44}$. Postura ésta que se concretaría tanto en los acuerdos del Lago Meech en $1987^{45}$ como en los de Charlottetown en $1992^{46}$, pues en ambos se dispuso que el Gobierno federal nombraría a los magistrados de la Corte Suprema de entre una lista de nombres proporcionados por los gobiernos de las provincias y los territorios. En suma, aunque ninguno de los tres intentos de hacer "mega Constitutional politics" acabó materializándose, que en todos ellos se acordara otorgar a las provincias una mayor participación en el nombramiento de los magistrados hace suponer que había consenso en relación a ello y que no fue ésta la razón que hizo

42 Es la época donde, en base a los principios del federalismo, se trató, sin éxito, de realizar entre las provincias y el Gobierno Federal profundas modificaciones constitucionales en ámbitos tan dispares como el Senado, la Corte Suprema o la división de poderes.

43 MCWHINNEY (1986), p. 73.

44 CRandall (2013), pp. 75-76; Leith (2009), pp. 26-27. Quienes se oponían a dicha política argumentaban que, si se llegaba a materializar el acuerdo, las provincias tendrían mucho poder para determinar la orientación política de la Corte Suprema. En cambio, los favorables al acuerdo del Lago Meech afirmaban que dicha fórmula generaba una mayor equidad entre los dos niveles de gobierno, otorgando legitimidad al sistema.

45 La propuesta de Constitutional Amendment, 1987, section 6.

46 Consensus Report on the Constitution, Charlottetown, 28 August 1992; Russell (2017), p. 4; LEITH (2009), p. 35. 
fracasar los acuerdos ${ }^{47}$. De hecho, una de las críticas más frecuentes a la época de los "mega constitutional politics" es que, al pretender realizar todas las modificaciones en bloque, el fracaso de las grandes negociaciones impidió que se llevaran a cabo pequeñas reformas sobre las que existía un acuerdo unánime.

Asimismo, si bien de forma mucho más tímida y a sabiendas que el Primer Ministro Jean Chréstien había afirmado que desoiría cualquier propuesta de reforma constitucional para evitar otra época de fracasos como la vivida entre 1970 y 1992, algunas voces todavía se levantaron durante su mandato (1993-2003) para exigir que los nombramientos de los jueces de la Corte Suprema se hicieran en base a los principios del federalismo. Nos referimos al Primer Ministro de Ontario Mike Harris que, en 1999, hizo un llamamiento para que las provincias tuvieran algún tipo de intervención en el sistema de nombramiento de los magistrados de la Corte Suprema. Al Partido Liberal de Quebec que, en 2001, publicó un documento donde abogaba por desarrollar los acuerdos alcanzados en el Lago Meech ${ }^{48}$. Y a la Council of Federations que, en 2004, pidió la formación de un comité para crear una nueva fórmula de nombramiento de los magistrados de la Corte Suprema que asegurara una adecuada participación de las provincias y los territorios ${ }^{49}$.

En definitiva, aunque ninguna de las propuestas acabó prosperando, de modo que los magistrados de la Corte Suprema siguen siendo elegidos formalmente por el Gobierno federal, dos realidades se hicieron presentes durante dicho periodo. La primera fue que, al convertirse en vértice del sistema judicial de la Federación y ostentar un gran poder al dirimir en último lugar cuestiones relativas a la distribución de competencias, la Corte Suprema pasó a ser analizada en base a los principios del federalismo. Y la segunda fue que, como consecuencia de esa nueva forma de aproximarse al máximo intérprete constitucional, hubo un amplio consenso en que existía un déficit federal en relación al nombramiento

47 Cf. CRandall (2013), p. 76.

48 A project for Quebec. Affirmation, Autonomy and Leadership.

49 Crandall (2010), p. 9. 
de los jueces de la Corte Suprema, cuestión por la cual las soluciones propuestas fueron aceptadas de manera casi unánime, no siendo dicha cuestión uno de los escollos por los cuales fracasaron los pactos durante la época de los "mega Constitutional politics".

\subsubsection{El debate sobre el procedimiento y los criterios de selección}

Esta segunda problemática se dará desde 1990 en adelante. Aunque entre 1982 y los primeros compases de los años noventa todavía existió una fuerte corriente de pensamiento que analizó al máximo intérprete constitucional en base a los principios del federalismo, proponiendo fórmulas para eliminar ese "déficit federal" a través de implicar a los dos órdenes de gobierno en el nombramiento de los jueces (Lago Meech y Charlottetown), la entrada en vigor de la Carta de Derechos y Libertades incluida en la CA de 1982 cambió la función que la Corte Suprema tenía que desempeñar y acabó modificando la manera a través de la cual dicha institución sería analizada. Es decir, como a partir de 1982 dicho tribunal pudo revisar el contenido de cualquier legislación y aumentó exponencialmente su capacidad de incidir sobre la realidad político-social canadiense ${ }^{50}$, los debates en relación a la institución fueron mudando en un doble sentido. Por un lado, se empezó a discutir sobre los límites del "activismo judicial" ${ }^{51}$, pues el principio de soberanía parlamentaria que había regido hasta el momento chocaba frontalmente con la constitucionalización de los derechos y la función que a partir de entonces se le otorgaba a la Corte Suprema ${ }^{52}$. Y, por otro lado, comenzó dicho tribunal a ser

50 Dicha cuestión se hizo socialmente patente entre 1988 y 1989 tras los casos Morgentaler vs. The Queen y Andrews v. Law Society of British Columbia.

51 DODEK (2017), p. 85.

52 En 2007, el Ministro de Justicia Irwin Cotler manifestó: "The Charter increased the visibility and importance of the role of the courts, and rightly so in the sense that we moved from being a parliamentary democracy to a constitutional democracy. We moved from the sovereignty of Parliament to the sovereignty of the constitution. We moved from judges being the arbiters of legal federalism, which they still are, to judges being the guarantors of our rights under the Charter because we, Parliament, gave that authority to judges not because they usurped it. And individuals and groups are no longer passive bystanders to a constitutional process; they are now rights holders and rights claimants. So clearly, the change in the constitutional framework and the advent of 
analizado en base a los principios democráticos, afirmándose que existía un déficit en tal sentido porque si la Corte Suprema tenía el poder para decidir sobre cuestiones morales, políticas y sociales, debía garantizarse que los ciudadanos conocieran tanto el procedimiento como los criterios de selección mediante los cuales eran escogidos los magistrados ${ }^{53}$.

Por tanto, la introducción de la Carta de Derechos y libertades creó factores adicionales que acabaron modificando el prisma a través del cual se examinarían algunos de los elementos esenciales de la Corte Suprema, siendo el "déficit democrático" 54 y el "activismo judicial" los puntos de partida de unos debates que fueron suplantando al "déficit federal" como foco de preocupación. A partir de entonces, medios de comunicación, académicos, jueces y líderes políticos empezaron a manifestar que, al ostentar la Corte Suprema un gran poder sobre cuestiones política y socialmente controvertidas, disminuía la importancia de quien nombraba formalmente a los magistrados a la par que aumentaba el valor tanto del procedimiento como de los criterios a través de los cuales eran escogidos $^{55}$. En definitiva, como quiera que la Carta de Derechos y libertades de 1982 modificó las funciones de la Corte Suprema, los debates en relación a ésta se fueron trasladando desde los principios del federalismo a los principios democráticos, alterándose tanto los parámetros de análisis como las soluciones propuestas ${ }^{56}$.

the Charter made the role of judges more public, more significant and therefore increased interest in the appointments process because of the increased impact of the judiciary in a post-Charter universe. Having said that, the actual impetus for the reform was actually the former Prime Minister Paul Martin because he was the one who said he wanted to correct the democratic deficit and he gave as an example of the democratic deficit the absence of parliamentary and provincial participation in Supreme Court appointments process". Cf. COTLER (2007).

53 PEACH (2005), p. 2; RUSSELL (2017), p. 6.

54 Dodek (2014), pp. 139-140.

55 Una breve bibliografía de ese cambio de perspectiva es la siguiente. En cuanto a los medios de comunicación, véase: Bernard (1997); Schratz (1997); Simpson (1997); Speirs (1997). Por lo que respecta a los jueces, véase: "La Forest favours Us-style public review for Supreme Court judges" (1997). En cuanto a la academia, véase: FrIEDLAND (1995); Russell (2004); McCoRmick (2005); Nadler (2006); Macfarlane (2005); Ziegel (2001); Manfredi (2003); Manahan y Hogg (2004); MoRTON (2006); KNOPFF (2008). Asimismo, gran parte de esta bibliografía puede encontrarse en CRANDALL (2013), pp. 5-6.

56 Eisenstat (1989), pp. 109-143; “Introduction”, (1991), p. 1; Whyte (2016), p. 110; Leith (2009), p. 54; PEACH (2005), p. 3. 
Aunque esas ideas empezaron a exponerse públicamente durante los años $90^{57}$, no sería hasta los inicios del siglo XXI que se convertirían en una cuestión política de primer orden, ejecutándose diferentes reformas en base a las mismas. En 2003, el Bloc Québécois, a través de Richard Marceau y con el apoyo del resto de grupos parlamentarios, presentó la moción-28858 en la Cámara de los Comunes para que el Committee of Justice and Human Rights de la propia Cámara (en adelante JUST) iniciara un estudio sobre la manera en que se hacían los nombramientos de la Corte Suprema y cómo podían mejorarse. Pese a que el 4 de febrero de 2004 el Primer Ministro Paul Martin, que desde el primer momento había demostrado interés en desarrollar una agenda para paliar el "déficit democrático" canadiense ${ }^{59}$, realizó dicha consulta al JUST ${ }^{60}$, la premura por tener que suplir dos jubilaciones de magistrados de Ontario hizo que las recomendaciones que dicha Comisión finalmente trasladó el Gobierno tuvieran dos partes: para el corto plazo (léase el nombramiento de los dos jueces de Ontario) aconsejó que el Ministro de Justicia compareciera delante del propio JUST para explicar el procedimiento seguido, mientras que para el largo plazo sugirió la creación de un Comité asesor (formado por parlamentarios, miembros del gobierno provincial, jueces, abogados y académicos con prestigio) que elaborara una lista de 3 candidatos de entre los cuales el Primer Ministro podría elegir ${ }^{61}$.

57 Ya en 1989, en el seno de la Ontario Law Reform Commission, se reconoció que otorgar a las provincias un papel en el nombramiento de los magistrados de la Corte Suprema no hacía que dicho proceso fuera más meritocrático y neutral. Asimismo, Preston Manning, líder de un Reform Party que en la década de los 90 tuvo gran importancia a la hora de identificar los déficits democráticos de Canadá y proponer soluciones, llegó a afirmar que como la Carta había otorgado a la Corte Suprema un estatus de "policy-maker", los magistrados de la Corte Suprema debían ser elegidos por y rendir cuentas a la gente. Cf. PEACH (2005), p. 3; CRAndall (2013), p. 6.

58 Dicha moción-288 se tituló "That the Standing Committee on Justice and Human Rights study the process by which judges are appointed to Courts of Appeal and to the Supreme Court of Canada." Journals of the House of Commons, 1 October 2003, p. 1077. Cf. LAWLOR (2015), p. 866.

59 Liberal Party of Canada, Moving Canada Forward: The Paul Martin Plan for Getting Things Done, (Ottawa: Liberal Party of Canada, 2004), p. 7; Privy Council Office, Ethics, Responsibility, Accountability: An Action Plan for Democratic Reform (Ottawa: Privy Council Office, February 4 2004).

60 House of Commons Debates, Num. 3 (4 February 2004). Cf. Cotler (2008), p. 134.

61 Standing Committee on Justice, Human Rights, Public Safety and Emergency Preparedness, Improving the Supreme Court of Canada Appointments Process, May 2004, p. 4-9; LeE (2004), p. 
Al seguir el Gobierno de Paul Martin la recomendación a corto plazo, 2004 fue el momento que, por primera vez en la historia, se hizo público algo más que la existencia de las vacantes. Aunque no comparecieron los candidatos escogidos, el Ministro de Justicia Irvin Cotler se personó el 30 de marzo frente al JUST ${ }^{62}$ para explicar el procedimiento seguido para nombrar a Rosalie Silberman Abella y Louise Charron ${ }^{63}$. Éste afirmó que dicho proceso tenía dos fases. En la primera el Ministro de Justicia identificaba potenciales candidatos consultando a varios miembros de la comunidad jurídica ${ }^{64}$, mientras que en la segunda evaluaba a los candidatos surgidos en base a cinco criterios: capacidad profesional, características personales, posible contribución a la institución, bilingüismo y diversidad ${ }^{65}$. Una vez realizadas ambas fases, el Ministro de Justicia discutía los candidatos con el Primer Ministro y el escogido era formalmente designado por el Governor in Council6.

La casualidad quiso que, en 2005 , tuviera que cubrirse otra vacante (la de las praderas), lo que permitió al mismo Gobierno desarrollar para dicha elección un procedimiento que constaba de cuatro fases ${ }^{67}$ y que estaba basado en las recomendaciones a largo plazo realizadas por el $\mathrm{JUST}^{68}$. Primero, el Ministro de Justicia realizaría las tradicionales con-

290; LEITH (2009), p. 6.

62 A dicho Comité, que normalmente estaba formado por 7 parlamentarios de las distintas fuerzas políticas en base a la representación que ostentaban en la Cámara de los Comunes, se le unieron 1 representantes del Canadian Judicial Council y otro del Law Society of Upper Canada. Cf. LAWLOR (2015), pp. 866-867; Russell (2017), p. 6; LeITH (2009), p. 8.

63 Pese a que formalmente fueron nombradas después de la comparecencia del Ministro de Justicia frente al Comité, este último únicamente tenía como función conocer el sistema actualmente existente y plantear modificaciones al mismo. Cf. LeE (2004); Hogg (2013), p. 5.

64 Los miembros normalmente consultados eran: al presidente de la Corte Suprema, otros jueces de la Corte Suprema, el presidente de la Corte Superior de Justicia, el Fiscal general de la provincia donde se debía elegir el juez, miembros destacados del colegio de abogados de la provincia, miembros de la academia de la provincia y el Departamento de Justicia.

65 Hogg (2006), p. 528; The new process for judicial appointments to the supreme court of Canada, Report of the Standing Committee on Justice and Human Rights, February 2917, 42 Parliament, 1st Session; Sossin (2013), pp. 41-42.

66 Verrelli (2013), p. 117; Lee (2004), pp. 2-3; Peach (2005), pp. 5-11; Cotler (2008), pp. 136-137.

67 Proposal for Reform to the Supreme Court Appointment Process, Government of Canada, 2005.

68 También hay que tener presente que, por esas fechas, en el Reino Unido se estaba llevando 
sultas para obtener posibles candidatos. Segundo, entregaría una lista de entre 5 y 8 aspirantes a un Comité asesor formado por 9 miembros ${ }^{69}$ que los evaluaría de manera secreta y en base a criterios meritocráticos. Tercero, dicho Comité proporcionaría una lista sin clasificación de entre 3 y 5 candidatos al Ministro de Justicia, discutiéndola éste último con el Primer Ministro a efectos de escoger definitivamente. Y cuarto, el Ministro de Justicia debería comparecer ante el JUST para explicar los motivos del nombramiento ${ }^{70}$.

Aunque un adelanto electoral y la posterior victoria conservadora paralizaron el procedimiento cuando el Comité asesor ya había entregado una lista de 3 candidatos $^{71}$, el recién estrenado Gobierno de Stephen Harper (2006) decidió continuar con el procedimiento ya iniciado pero le añadió una audiencia pública para el candidato escogido ${ }^{72}$. Así pues, una vez el Ejecutivo se decantó por Marchall Rothstein como nuevo juez de la Corte Suprema, y antes de nombrarlo formalmente ${ }^{73}$, éste tuvo que exponerse a una sesión televisada de 3 horas en la que una comisión de 12 parlamentarios ${ }^{74}$ le formularon preguntas relativas a sus cualidades tanto profesionales como personales. A pesar de que dicha comisión ni

a cabo un debate similar donde ya se había introducido una propuesta de ley para que las vacantes a la recién creada Corte Suprema se nombraran a través de un Comité de selección. Cf. Constitutional Reform Bill (Bill 18), section 24; PEACH (2005), pp. 7-8.

69 Para dicha selección específica, los nueve miembros se repartían de la siguiente manera: 4 parlamentarios uno de cada partido, un juez retirado elegido por el Canadian Judicial Council, un juez escogido por la Law Society of the Prairie, un representante de los 3 Prairie provincial Government y dos personas independientes de indiscutible integridad y distinción elegidas por el gabinete.

70 Como había sucedido también en 2004, pese a que formalmente dichos nombramientos se hicieron después de la comparecencia del Ministro de Justicia frente al Comité, dicho Comité únicamente tenía como función evaluar el Primer Ministro y su forma de elección, no al candidato escogido. Cf. Beg y Sossin (2018), p. 131; Russell (2017), pp. 6-7; Leith (2009), p. 9; Cotler (2008), pp. 143-146.

71 DODEK (2014), pp. 123-125.

72 Según el Primer Ministro Harper, "The Supreme Court is a vital institution that belongs to all Canadians ... the public deserves to know more about the individuals appointed to serve there, and the method by which they are appointed". Cf. Prime Minister of Canada, "News Release: Supreme Court Nominee to Face Questions from Parliamentarians" (February 20, 2006).

73 El primer ministro confirmó el nombramiento dos días después de la aparición televisiva.

74 La proporción fue la siguiente: 5 conservadores, 4 liberales, 2 del Bloc Québécois y 1 del New Democratic Party. 
votó ni redactó ningún informe ${ }^{75}$, el trámite añadido por el gobierno de Stephen Harper tuvo dos consecuencias principales. Primero, favoreció que la rendición de cuentas fuera del poder legislativo al candidato y no al poder ejecutivo, pues quien tuvo que comparecer frente a la Comisión fue Marchall Rothstein y no el Ministro de Justicia ${ }^{76}$. Y, segundo, comportó una apertura del proceso a la sociedad canadiense, pues, aunque siguió siendo opaca la presentación de candidaturas, la deliberación del Comité asesor y la elección por parte del Ejecutivo, la posterior comparecencia pública facultaba que los ciudadanos pudieran conocer los méritos por los cuales el candidato iba a ser nombrado juez de la Corte Suprema ${ }^{77}$. Seguramente por ello, cuando el Primer Ministro Harper anunció el nombramiento de Marchall Rothstein afirmó:

"The way in which Justice Rothstein was appointed marks an historic change in how we appoint judges in this country. It brought unprecedented openness and accountability to the process. The hearings allowed Canadians to get to know Justice Rothstein through their members of Parliament in a way that was not previously possible"78.

Como quiera que cada vez que surgía una vacante podía gestarse una fórmula nueva al no estar el procedimiento supeditado a ninguna ley, pues éstos se creaban a través de unas decisiones administrativas del Gabinete Ilamadas Order-in-Council79, el Gobierno de Stephen Harper acabó por desvirtuar el proceso de las otras 7 nominaciones que hizo durante su mandato. Y ello es así porque, o bien el Comité asesor estaba mayoritariamente formado por miembros de su partido, o bien la posterior comisión evaluadora pública estaba compuesta en su mayoría por miembros de su partido o bien fueron nombrados directamente por el Ejecutivo

75 Dodek (2014), pp. 118-126.

76 Trataba de imitarse al mecanismo estadounidense del "Supreme Court nomination hearings" realizado por el Senado de dicho país.

77 Aiello (2013), p. 290; Leith (2009), p. 10.

78 "Prime Minister announces appointment of Mr. Justice Marshall Rothstein to the Supreme Court" (March 1, 2006).

79 La Order in Council a través de la cual se crean los Independent Advisory Board es el número: P.C 2016-0693. 
sin ningún tipo de procedimiento conocido ${ }^{80}$.

No sería hasta la victoria de Justin Trudeau en los comicios de 2015 que habría una sustancial modificación tanto del procedimiento como de los criterios de selección de los jueces de la Corte Suprema. Durante su campaña, el partido liberal afirmó que si ganaba las elecciones crearía un sistema de selección de magistrados que fuera transparente, público, inclusivo, meritocrático, despolitizado y donde existiera verdadera rendición de cuentas. La jubilación del magistrado Thomas Cromwell en septiembre de 2016 permitió al nuevo Gobierno de J. Trudeau poner en práctica todo lo anteriormente afirmado a través del desarrollo de un nuevo procedimiento.

La columna vertebral de este nuevo sistema fue la creación de un $A d-$ visory Board for Supreme Court Appointments de carácter independiente, despolitizado, no vinculante y cuya función era identificar potenciales candidatos que fueran idóneos para ser escogidos como magistrados de la Corte Suprema. Dicho Comité asesor estaba formado por 7 miembros $^{81}$ que debían reflejar la diversidad de la sociedad canadiense ${ }^{82}$, siendo frente al mismo que todo ciudadano podía proponerse como candidato a través de contestar un cuestionario que, de ser finalmente elegido, se haría público. Asimismo, dicho Comité asesor también se encargaba tanto de informar a las principales asociaciones jurídicas para que hicie-

80 Aquellos que fueron nombrados sin que mediara Comité asesor ni Comisión evaluadora fueron: Thomas Cromwell (2008), Clément Gascon (2014), Suzanne Côte (2014) y Russell Brown (2015). En cambio, en los que hubo un Comité o Comisión mayoritariamente formado por miembros del partido conservador fueron: Andromache Karakatsanis (2011), Michael J. Moldaver (2011), Richard Wagner (2012). Para conocer con más detalle dichos procedimientos véase: Cf. DODEK (2014), pp. 126-130; BEg y Sossin (2018), pp. 132-134; RUSSELL (2017), p. 7; LAWLOR (2015), pp. 863-873; Aiello (2013), p. 291; Hogg (2013), p. 17; Sossin, (2013), p. 41.

81 Cuatro eran escogidos por y de entre las diferentes organizaciones jurídicas (debían ser un juez retirado nombrado por el Canadian Judicial Council; un abogado seleccionado por el Canadian Bar Association y otro por la Federation of Law Societies of Canada; un académico nombrado por el Council of Canadian Law Deans) y los otros tres seleccionados por el Ministro de Justicia (de los cuales dos no podían ser abogados). Cf. Report of the Independent Advisory Board for Supreme Court of Canada Judicial Appointment, August-September 2016, p. 2-3.

82 El compuesto en 2016 tenía un miembro de cada una de las regiones, paridad mujer/hombre y diversidad étnica. Cf. Russell (2017), p. 8. 
ran sugerencias ${ }^{83}$ como de enviar mensajes para que postularan aquellas personas a las que dichas asociaciones hubieran sugerido.

Una vez cerrado el periodo de presentación de candidaturas, el Comité asesor decidía qué 3 o 5 candidatos proponía al Gobierno en base tanto a los requisitos legales de elegibilidad fijados en la Supreme Court Act como a los criterios que el propio Ejecutivo había instaurado discrecionalmente para que el Comité realizara su función. Mientras los requisitos legales eran que como mínimo 3 magistrados debían provenir de Quebec y que todos debían ser escogidos de entre quienes son o hubieran sido jueces de la Corte Superior de la Provincia o abogados con 10 años de pertenencia al Colegio de Abogados provincial; los criterios establecidos por el Ejecutivo eran los siguientes: que fueran funcionalmente bilingües ${ }^{84}$, que demostraran un conocimiento superior de la ley, que poseyeran gran capacidad analítica, que tuvieran habilidad para resolver problemas complejos y para sintetizar información sobre disputas legales, que pudieran trabajar bajo presión, que poseyeran una irreprochable integridad profesional y personal, que hubieran demostrado compromiso con el servicio público y, por último, también era perentorio que se tuviera en cuenta que la Corte Suprema debía reflejar la diversidad canadiense, poseer equilibrio de género y tener expertos en los diferentes ámbitos legales ${ }^{85}$.

83 Las asociaciones consultadas fueron las siguientes: Canadian Judicial Council, Federation of Law Societies of Canada, Canadian Bar Association; Council of Canadian Law Deans, Canadian Superior Courts Judges Association, Canadian Association of Provincial Court Judges, Canadian Council of Chief Judges; Indigenous Bar Association; Ukrainian-Canadian Bar Association y la Roundtable of Diversity Associations (formada por la Arab Canadian Lawyers Association, Association of Chinese Canadian Lawyers of Ontario, Canadian Association of Black Lawyers, Canadian Association of South Asian Lawyers, Canadian Hispanic Bar Association, Canadian Italian Advocates Organization, Canadian Muslim Lawyers Association, Federation of Asian Canadian Lawyers, Hellenic Canadian Lawyers Association, Iranian Canadian Legal Professionals, Korean Canadian Lawyers Association, Macedonian Canadian Lawyers Association, OBA Equality Committee, Sexual Orientation and Gender Identity Conference, South Asian Bar Association, Toronto Lawyers Association, and Women's Law Association of Ontario). Cf. Report of the Independent Advisory Board for Supreme Court of Canada Judicial Appointment..., p. 6; The new process for judicial appointment to the Supreme Court of Canada, Report of the Standing Committee on Justice and Human Rights, February 2017, 42 Parliament, 1st Session, p. 5.

84 Lo que significa que puedan leer, escribir y entender perfectamente ambos idiomas.

85 Government of Canada, Qualifications and Assesment Criteria, 2 August 2016; Report of the 
Una vez la lista estaba en poder del Ministro de Justicia, que además recibía un documento adjunto donde se detallaban los méritos de cada uno de los candidatos, ésta era consultada con el Presidente del Tribunal Supremo de Canadá, el Procurador General de la provincia en cuestión y algunos miembros tanto de la judicatura como del Parlamento. Por último, una vez realizada la elección definitiva por parte del Ejecutivo, tanto el Ministro de Justicia como el candidato escogido debían comparecer frente al JUST, el primero para explicar los motivos de la elección y el segundo para responder a sus preguntas ${ }^{86}$.

Este nuevo procedimiento a través del cual en 2016 se nombró a Malcolm Rowe magistrado de la Corte Suprema, fue prácticamente idéntico al utilizado en 2017 para escoger a Sheila L. Martin y muy similar al empleado en 2019 para elegir a Nicholas Kasirer.

Comparado con el de 2016, en el proceso de 2017 sólo hubo una pequeña pero significativa diferencia ${ }^{87}$. Entre los criterios que el Gobierno de J. Trudeau había establecido en 2016 para que el Comité asesor seleccionara candidatos no se encontraba la necesidad de cumplir con aquel equilibrio regional que había venido siendo un consenso político desde la creación de la Corte Suprema, de tal manera que una vez abierta la fase de selección cualquier canadiense pudo presentar candidatura (de hecho, hubo 31 aspirantes de 7 provincias diferentes ${ }^{88}$ ). Aunque al escoger a Malcolm Rowe se respetó el equilibrio regional, pues la vacante era de las provincias Atlánticas y dicho juez provenía de Newfoundland y Labrador, el temor a que fuera el primer paso para romper el consenso político alrededor del equilibrio regional en el seno de la Corte Suprema hizo que la oposición pasara una resolución donde se pedía al Gobierno seguir respetando "la costumbre de la representación territorial"

Independent Advisory Board for Supreme Court of Canada Judicial Appointment..., pp. 18-27. 86 Beg y Sossin (2018), pp. 136-137; Russell (2017), pp. 2-3.

87 Report on 2017 Process of the Independent Advisory Board for Supreme Court of Canada Judicial Appointment, January 17, 2018, p. 3.

88 Report of the Independent Advisory Board for Supreme Court of Canada Judicial Appointment, August-September 2016, p. 7.

89 MACKAY (2017), pp. 1-3 
tión que también remarcaría posteriormente el informe del JUST al recomendar que la obtención de una mayor diversidad en el interior de la Corte Suprema no se hiciera a expensas de la representación regional que históricamente en ella existía ${ }^{90}$. Quizás por las críticas y sugerencias anteriores, se realizaría la siguiente especificación al Comité asesor para la selección de candidatos en el procedimiento de 2017,

"In recognition of the custom of regional representation, the process was open to all qualified candidates from Western Canada and from Northern Canada. Candidates who wished to be considered were required to complete and submit applications by September 15, 2017"91

Asimismo, el procedimiento desarrollado en 2019 mediante el cual se acabó escogiendo a Nicholas Kasirer tuvo tres novedades respecto a los dos anteriores. La primera es que se creó un Comité asesor específico para Quebec formado por 8 miembros, participando en su selección también el gobierno regional y siendo mayoría en él quienes procedían del propio Quebec. La segunda es que se dio un papel más activo al Ejecutivo provincial, pues una vez finalizada la tarea del Comité asesor, el Ministro de Justicia de Canadá debía trasladar los nombres al Ministro de Justicia de Quebec y al Primer Ministro de Quebec para que hicieran sus propias consultas, devolviendo éstos finalmente la lista al Primer Ministro Canadiense con sus recomendaciones. Y la tercera es que se bifurcó la forma en la que se hacía la rendición de cuentas, pues primero el Ministro de Justicia y el presidente del Comité asesor debían comparecer delante del JUST para justificar la elección de Nicholas Kasirer, mientras que, después de haber sido éste escogido, el candidato debía comparecer en una sesión pública donde no sólo participaba el JUST, sino también el Comité de asuntos legales del Senado y miembros de los partidos políticos de la Asamblea legislativa de Quebec $^{92}$.

90 The new process for judicial appointment to the Supreme Court of Canada..., p. 8.

91 Report on 2017 Process of the Independent Advisory Board for Supreme Court of Canada Judicial Appointment..., p. 2.

92 Toda esta información puede ser obtenida de las siguientes dos páginas webs institucionales: https://pm.gc.ca/en/news/backgrounders/2019/05/15/arrangement-concerning-appointment-process-fill-seat-will-be-left y https://www.fja-cmf.gc.ca/scc-csc/2019/establishment-creation-eng.html. 
En definitiva, es plausible afirmar que, desde los años noventa hasta febrero de 2019, en Canadá se ha ido gradualmente modificando tanto el procedimiento como los criterios de selección de los magistrados de la Corte Suprema partiendo de la premisa que existía un "déficit democrático" y que el objetivo era hacer que todo el proceso fuera transparente, público, inclusivo, meritocrático, despolitizado, representativo de la sociedad canadiense y sujeto a una verdadera rendición de cuentas. Si bien el Reform Party fue el primer instigador de todo ello, el Gobierno de Paul Martin su primer ejecutor y el de Stephen Harper el introductor de las audiencias públicas (aunque luego corrompiera el proceso), ha sido el Ejecutivo comandado por J. Trudeau quien ha ido desarrollando un procedimiento que parece cumplir con todos los objetivos que teóricamente se perseguían desde el inicio.

Y eso es así por las siguientes razones. Primero, porque crea un Comité asesor despolitizado e independiente que no está formado por ningún parlamentario y que realiza su tarea al margen del Gobierno de turno. Segundo, es un sistema meritocrático porque los criterios en base a los cuales el Comité asesor debe seleccionar así lo son. Tercero, es inclusivo, público y transparente porque cualquier ciudadano canadiense puede proponerse como candidato, los informes del Comité asesor son públicos (proporcionando información detallada de los aspirantes) y la sociedad canadiense puede conocer los méritos por los cuales un candidato ha sido escogido dado que tiene acceso a la comparecencia que hace el Ministro de Justicia, el presidente del Comité asesor y el candidato frente a una comisión de representantes políticos. Cuarto, es representativo de la sociedad canadiense porque el Comité asesor debe reflejar la diversidad de la comunidad política y porque se pide a las principales asociaciones jurídicas que le hagan sugerencias de aspirantes. Quinto, promueve tanto el federalismo intra-estatal como la confianza ciudadana al permitir a todos los órganos políticos del Estado intervenir y obligarles a colaborar, de manera que se refuerzan los lazos institucionales dentro de la Federación y se traslada a la ciudadanía la percepción de consenso sobre la idoneidad de los magistrados de la Corte Suprema. Y sexto y último, existe una verdadera rendición de cuentas de todo el procedimiento hacia el 
Legislativo, pues el Ministro de Justicia, el presidente del Comité asesor y el candidato escogido deben comparecer frente a una comisión que está formada enteramente por representantes políticos (parlamentarios, senadores y miembros de partidos políticos de las Asambleas legislativas provinciales).

Asimismo, aunque la juventud del nuevo procedimiento (2016) y las pocas vacantes que se han rellenado a su través (sólo 3) hacen imposible que tengamos una perspectiva histórica suficientemente amplia como para valorar si sus nombramientos son más representativos de la diversidad cultural que existe en el interior de Canadá o con un grado menor de politización, sí que es posible dar algunos datos sobre el pasado que debería tenerse en cuenta en futuros análisis. En primer lugar, que desde 1982 cuando Bertha Wilson fue la primera mujer elegida magistrada de la Corte Suprema, 9 mujeres han sido escogidas para el cargo, existiendo en 2019 un equilibro de género en el cual 4 de los 9 miembros del tribunal son féminas. En segundo lugar, que ciertos sectores consideran que hasta el momento la diversidad canadiense no ha tenido su completo reflejo en el seno de la institución, pues si bien es verdad que el haber un número reducido de plazas y ostentarse el cargo hasta los 75 años dificulta sobremanera la posibilidad de que todas las sensibilidades culturales pueden verse representadas, no es menos cierto que hasta 2019 no se ha nombrado ningún juez que provenga de alguno de los pueblos originarios reconocidos en el seno de la Federación ${ }^{93}$. Ahora bien, lo anterior no puede ocultar que sí han accedido a él minorías como podrían ser judíos, homosexuales o personas nacidas en otros países. Y, en tercer y último lugar, aunque la opacidad del procedimiento haya comportado que hasta 2004 se creyera que éste estaba politizado, los estudios rea-

93 Una de las críticas que ha recibido el procedimiento establecido por el Gobierno de J. Trudeau es que el criterio de ser funcionalmente bilingües disminuye las posibilidades de los colectivos indígenas para aspirar a formar parte de la Corte Suprema, pues se prioriza a candidatos que hablen inglés y francés frente a otros que hablan inglés y otro idioma nativo. Además, la obligatoriedad de que existan 3 jueces de Quebec, pero ninguno indígena también ha sido criticada por dichas comunidades. Cf. Indigenous Bar Association Calls upon the Government of Canada to Reconsider its Requirement of "Functional Bilingualism" As It Applies to Indigenous Candidates for Appointment to the Supreme Court', Nation Talk, 22 August 2016. 
lizados durante las últimas décadas demuestran que ya desde 1960 la meritocracia y el respeto a la diversidad provincial fueron la regla a seguir para los nombramientos ${ }^{94}$. Cuestión que, a su vez, nos permite una doble aseveración. Uno, que quizás por ello la población ostenta una opinión muy favorable tanto de la institución como de sus magistrados ${ }^{95}$. $Y$ dos, que cuando desde los años noventa se empezó a afirmar que la Corte Suprema adolecía de un "déficit democrático", en ningún momento se quiso aseverar que los magistrados escogidos no tuvieran las cualidades técnicas necesarias para formar parte de la institución, sino que el procedimiento a través del cual éstos habían sido seleccionados no respondía a los principios democráticos de publicidad, transparencia, inclusividad, meritocracia, representatividad y rendición de cuentas.

\section{Conclusiones}

Parece evidente que la estructura territorial del Estado (descentralizado o centralizado), la forma de Gobierno (parlamentario o presidencialista) y el tipo de magistratura constitucional ${ }^{96}$ que se establece en la Carta Magna influyen de manera directa en el modo en que se determina el quién, el cómo y en base a qué criterios se nombran los miembros del Tribunal Constitucional ${ }^{97}$. Para poner sólo un ejemplo, normalmente,

94 Dodek (2014), pp. 118-119; Snell y Vaughan (1985), pp. 197-251.

95 Fletcher y Howe (2001); Nanos (2007), p. 50; Macfarlane (2009), p. 258-265.

96 Marcos Libedinsky Tschorne (2003), p. 2-3 hace un buen resumen de ello y afirma que "Eduardo Ferrer Mac-Gregor distingue cuatro grupos de tribunales: a) Tribunales o Cortes constitucionales autónomos ubicados fuera del poder judicial ordinario (Chile, Ecuador, España, Guatemala, Perú, Portugal); b) Tribunales o Cortes autónomos dentro de la propia estructura del Poder Judicial (Bolivia y Colombia); c) Salas especializadas en materia constitucional pertenecientes a las propias Cortes o Tribunales Supremos (El Salvador, Costa Rica, Nicaragua, Paraguay y Venezuela) y d) Cortes o Tribunales Supremos ordinarios realizando funciones de tribunal constitucional, aunque no de manera exclusiva (Argentina, Brasil, Honduras, México, Panamá y Uruguay) [...] Nestor Pedro Sagües coincide en recalcar que no hay un único tipo de magistratura constitucional sino al menos tres modalidades: a) tribunal especializado extra-poder (un tribunal al estilo del sistema austríaco diseñado por Hans Kelsen); b) Tribunal especializado autónomo dentro del Poder Judicial (Alemania); c) Tribunal especializado dentro de la Corte Suprema, tendencia de tipo transaccional en la cual el TC es una sala especializada de la Corte Suprema. Cf. FERRER (2002), pp. 65 y 66; SAGÜES (1998), p. 201.

97 Para un análisis de dicha cuestión en perspectiva comparada véase: SIMÓN (2013), pp. 357-390. 
cuando el Estado es políticamente descentralizado, la forma de Gobierno es parlamentaria y el Tribunal Constitucional se concibe como un órgano autónomo ubicado fuera del poder judicial ordinario, el nombramiento lo hacen mayoritariamente los órganos políticos del Estado, el procedimiento es diferente al de los demás órganos judiciales y los criterios de selección suelen pretender alcanzar un equilibrio ideológico-territorial.

En consonancia con lo anterior, en el Estado centralizado y presidencialista chileno, el artículo 92 inciso primero de su Constitución Política establece que tres ministros serán designados por el Presidente de la República, cuatro elegidos por el Congreso Nacional (dos directamente por el Senado, en votaciones únicas por 2/3 de los senadores en ejercicio y dos propuestos por la Cámara de Diputados para su aprobación o rechazo por parte del Senado; siendo en ambos casos en votaciones únicas por 2/3 de los senadores y diputados en ejercicio) y tres designados por la Corte Suprema (votación secreta en sesión especial). Además, los ministros durarán 9 años en el cargo, su renovación se realizará por parcialidades cada tres años, no pueden ser renovados o reelegidos en sus cargos como regla general, son inamovibles y cesarán en sus funciones a los 75 años. Asimismo, cabe destacar también que, entre los requisitos de elegibilidad se encuentran los siguientes: 15 años de título de abogado; haberse destacado en la actividad profesional, universitaria o pública; no afectarles inhabilidades para cargo de juez; incompatibilidad con cargo diputado, senador, empleos fiscales, semifiscales, empresas estatales, etc.; y no poder ejercer de abogado, incluyendo la judicatura, ni celebrar contratos con el Estado, ser director de S.A. o similar, entre otros.

Ahora bien, además de mantenerse el vínculo entre forma de Estado, de gobierno y procedimiento de selección de los magistrados del Tribunal Constitucional, también creemos que puede ser oportuno tener en cuenta otros principios que han ido apareciendo y consolidándose en el seno de la teoría democrática del Estado. Nos referimos, básicamente, a preceptos como transparencia, igualdad de género, publicidad, integración, meritocracia, rendición de cuentas o despolitización. Así pues, estimamos que el análisis sobre el procedimiento y los criterios de selección de los 
magistrados de la Corte Suprema de Canadá puede ser interesante para el actual debate constitucional chileno por los siguientes cinco motivos.

Primero, porque aunque existan tanto dos proyectos de reforma presentados (uno introducido por el Frente Amplio ${ }^{98}$ y otro por la expresidenta Bachele ${ }^{99}$ ) como una propuesta académica colectiva (el Informe final del Grupo de Estudio de Reforma al Tribunal Constitucional100) que tratan de realizar modificaciones sustanciales en relación al nombramiento de los ministros del Tribunal Constitucional a través de incorporar algunos de esos preceptos democráticos, todos ellos están esquemáticamente desarrollados y algunos sólo utilizan como referencia el sistema estadounidense ${ }^{101}$, de manera que el modelo canadiense puede servir tanto para

98 Su propuesta es la modificación del Art. 92 inciso primero para que el redactado sea el siguiente: "Habrá un Tribunal Constitucional integrado por diez miembros que serán elegidos a través del siguiente procedimiento: a) La Corte Suprema convocará a un concurso público, que contemple una audiencia pública en la que se deberán aplicar los mecanismos de participación ciudadana que establece la ley $\mathrm{N}^{\circ} 20.500$, concluido el proceso anterior elaborará una terna, que será enviada al Congreso Nacional, a la cámara que corresponda según la alternancia. b) El Senado elegirá a cinco de los miembros del Tribunal Constitucional, misma cifra elegirá la Cámara de Diputados, alternándose en la forma que corresponda. c) De la terna enviada por la Corte Suprema, la Cámara que corresponda procederá a elegir en votación individual, pública y celebrada especialmente para tal efecto, debiendo ser nombrado ministro el que obtenga la votación más alta de la terna. Cf. Boletín del Senado No11.680-07.

99 En dicho proyecto se quiere que el Tribunal Constitucional este integrado por diez miembros, designados según el siguiente procedimiento: a) La Corte Suprema convoca a un concurso público para formar una terna que elevará al Presidente de la República. b) El Presidente de la República propone a uno de los integrantes de dicha terna a las dos Cámaras de Congreso Nacional. c) Cada una de las dos Cámaras, con el respaldo afirmativo de dos tercios de sus miembros en ejercicio, dan su conformidad al candidato. d) El Presidente de la República designa al elegido, nombrándolo como Ministro del tribunal Constitucional. Para el cumplimiento de lo establecido en la letra c) anterior, y de forma previa a la votación, el candidato propuesto deberá formular una exposición de su postulación al cargo respectivo en una sesión especial y pública ante la Sala de la Cámara respectiva. Cf. Boletín del Senado No11.617-07.

$100 \mathrm{El}$ informe propone un aumento de los integrantes a 12 miembros, introducir directrices de equidad de género, limitar la discrecionalidad actual de las tres designaciones presidenciales, incorporando una precalificación por parte de una (nueva) comisión autónoma de nombramientos de altos magistrados, dos de los tres ministros designados por la Corte Suprema podrán ser designados de entre los ministros de la Corte Suprema y de las Cortes de Apelaciones del país y aumentar los estándares de transparencia, escrutinio público y participación de la sociedad civil en los procesos de selección respecto de todas las designaciones. Son las propuestas número 13, 14, 16, 17 y 18 (págs. 59-62).

101 En el propio Informe final del Grupo de Estudio de Reforma al Tribunal Constitucional se analiza con profusión el modelo americano, mientras el sistema canadiense es simplemente 
dar una perspectiva nueva como para profundizar en el cómo debería ser el desarrollo práctico del procedimiento de selección, máxime cuando éste ha sido recientemente reformado. Segundo, porque es una fórmula a través de la cual disminuye la importancia de quién es el detentador último de la decisión mientras aumenta la relevancia del procedimiento y los criterios de selección. Es cierto que en Canadá la potestad final recae en el Primer Ministro, pero no lo es menos que, tanto la implicación de una multiplicidad de actores institucionales y sociales como la publicidad del proceso constriñen la posible arbitrariedad o discrecionalidad del Primer Ministro. Tercero, porque es una fórmula que permite introducir tanto en el procedimiento como en los criterios de selección los principios de transparencia, igualdad de género, publicidad, integración, meritocracia, rendición de cuentas y despolitización sin la necesidad de efectuar una reforma constitucional. Cuarto, porque es un procedimiento que posibilita una doble rendición de cuentas: primero del ciudadano en relación a todo el proceso en base a la transparencia y luego del legislativo hacia el ejecutivo, el candidato y el Comité asesor a través de la comparecencia de éstos delante de una comisión de representantes políticos. Y quinto, porque es una fórmula que permite introducir la procedencia territorial del candidato entre los criterios de selección, de tal manera que la totalidad de los magistrados no pueda provenir de la misma zona geográfica.

En definitiva, estamos persuadidos que la solución canadiense en relación al proceso de nombramiento y los criterios de selección de su Corte Suprema pueden ser de gran interés para el actual debate constitucional chileno. Asimismo, y reiterando lo ya afirmado en la introducción, también estamos plenamente convencidos que no es nuestra tarea proponer una específica solución para Chile. Cuestión esta última que corresponde de manera exclusiva a un diálogo virtuoso entre ciudadanía, academia y poder político que actualmente se está produciendo alrededor del proceso constituyente. Siendo nuestro papel en dicho engranaje el de relatores de una experiencia que quizás enriquezca dicho debate e inspire soluciones.

nombrado. 


\section{Bibliografía}

"Introduction" (1991): en Appointing Judges: Philosophy, Politics and Practica (Ontario Law Reform Commission, Toronto).

Aiello, Jonathan (2013): "The Supreme Court of Canada: a chronology of change”, en The democratic dilemma. Reforming Canada's Supreme Court (McGill-Queen's University Press).

Bassa Mercado, Jaime (2015): "El tribunal constitucional en la Constitución chilena vigente”, en V.V.A.A, La Constitución chilena. Una revisión crítica a su práctica política, LOM.

BEG, Samreen y Sossin, Lorne (2018): "Diversity, transparency and inclusion in Canada's judiciary”, en Graham Gee and Erika Rackley (edit.), Debating judicial appointments in an age of diversity (Taylor \& Francis Books, New York).

Bernard, Malcolm (1997): "Selection of top-court judges should be more open: experts", en The Gazette (2 September).

BILodeau, Roger (2010): "Supreme Court of Canada - structure, status and challenges", en Commonwealth Law Bulletin (Vol. 36, No. 3, September).

Castellà Andreu, Josep Maria (2014): "Canadá: un laboratorio del federalismo”, en Solozábal, J. (ed.), La reforma federal. España y sus siete espejos (Biblioteca Nueva, S.L.).

Consensus Report on the Constitution, Charlottetown, 28 August 1992.

CRANDALl, Erin (2010): "Intergovernmental Relations and the Supreme Court of Canada: The Changing Place of the Provinces in Judicial Selection Reform", en Special Series on the Federal Dimensions of Reforming the Supreme Court of Canada (McGill University, SC Working Paper).

- (2013): "Intergovernmental Relations and the Supreme Court of Canada: The Changing Place of the Provinces in Judicial Selection Reform", en Nadia Verrelli (edit.), The democratic dilemma. Reforming Canada's Supreme Court (McGuill-Queen's University Press).

CotLeR, Irwin (2007): Personal Interview (20 February).

- (2008): "The Supreme Court Appointment Process: Chronology, Con- 
text and Reform", en University of New Brunswick Law Journal (Annual, Vol. 58, núm. 16).

Couso, Javier y Coddou, Alberto (2010): "Las asignaturas pendientes de la reforma constitucional chilena", en Claudio Fuentes (Ed.), En nombre del pueblo: Debate sobre el cambio constitucional en Chile (Heinrich Böll Stiftung e ICSO, Santiago).

Comparación de Proyectos de Reforma al Tribunal Constitucional.

Department of Justice (2004): Backgrounder - The Ad Hoc Committee (September 29)

Dodek, Adam M. (2014): "Reforming the Supreme Court Appointment Process, 2004-2014: A 10-Year Democratic Audit”, en The Supreme CourtLaw Review: Osgoode's Annual Constitutional Cases Conference (núm. 67).

- (2017): "From subservient Officers of the Crown to Independent Servants of the People: The supreme Court of Canadas Perceptions of itsel", Matthew P. Harrington (Edit.), The Court and the Constitution. A 150-year retrospective (LexisNexis, Toronto).

EISENSTAT WeINRIB, Lorraine (1989): "Appointing judges to the supreme court of Canada in the charter era. A study in institutional function and institutional design", Appointing Judges: Philosophy, Politics and Practice, (University of Toronto, Faculty of Law).

Ferrer MAC-Gregor, Eduardo (2002): Los tribunales Constitucionales en Iberoamérica (Fundación Universitaria de Derecho, Administración y Política, México).

Fletcher, Joseph F. y Howe, Paul (2001): "Public Opinion and Canada's Courts," Judicial Power and Canadian Democracy, Paul Howe and Peter H. Russell eds. (Montreal: McGill-Queen's University Press).

FriedLAND, Martin L. (1995): A Place Apart: Judicial Independence and Accountability in Canada, ed. Canadian Judicial Council (Ottawa: Canada Communication Group-Pub).

Government of Canada, Qualifications and Assesment Criteria, 2 August 2016

Herman, Michael John (1976): "The founding of the Supreme Court of Canada and the abolition of the appeal to the Privy Council”, en Ottawa 
Law Review (Vol. 8, Winter).

Hogg, Peter W. (2006): "Appointment of Justice Marshall Rothstein to the Supreme Court of Canada", en Osgoode Hall Law Journal (Vol. 44, Núm. 3).

(2013): "Appointment of Thomas A. Cromwell to the Supreme Court of Canada", en The democratic dilemma. Reforming Canada's Supreme Court (McGill-Queen's University Press).

Informe final del Grupo de Estudio de Reforma al Tribunal Constitucional.

4 propuestas para un Tribunal Constitucional del Siglo XXI, Santiago de Chile, 2019.

KNOPFF, Rainer (2008): "The Politics of Reforming Judicial Appointments.

(Canada)," University of New Brunswick Law Journal (núm. 58).

KWAVNIK, David (1973): The Tremblay Report, (McGill-Queen's University Press).

LAWLOR, Andrea (2015): "Questioning Judges with a Questionable Process: An Analysis of Committee Appearances by Canadian Supreme Court Candidates", en Canadian Journal of Political Science / Revue canadienne de science politique (Vol. 48, Núm. 4, December / décembre).

LeE, Derek (chair) (2004): "Improving the Supreme Court of Canada Appointments process", Report of the Standing Committee on Justice, Human Rights, Public Safety and Emergency preparedness, May.

LeItH, Gayle (2009): The Appointment Process for the Supreme Court of Canada: Assessing the Goals and Performance of the Supreme Court Selection Panel, (A Thesis submitted to the Faculty of Graduate Studies of the University of Manitoba).

Liberal Party of Canada (2004), Moving Canada Forward: The Paul Martin Plan for Getting Things Done, (Ottawa: Liberal Party of Canada).

LiBEDINSKY Tschorne, Ministro Marcos (2003): "Procedimiento de elección y nombramiento del juez constitucional”, (X encuentro de los presidentes y magistrados de los tribunales y salas constitucionales de américa latina, Santiago de Chile, 1 al 5 de septiembre).

MAccormick, Peter (2005): "Selecting the Supremes: The appointment of Judges to the Supreme Court of Canada", en The Journal of Apellate 
Practice and Process (Vol. 7, Núm. 1).

MacdonalD, Vincent (1951): "The Privy Council and the Canadian Constitution", en The Canadian Bar Review (Vol. XXIX, Num. 29).

MACFARLANE, Emmet (2005): "Reforming the Supreme Court of Canada Appointments Process: Politics, Transparency, and Judicial Independence", en Queen's University.

- (2009): The Supreme Court of Canada and the judicial role: an historical institutionalist account, "a thesis submitted to the Department of Political Studies, Queens's University, Kingston, Ontario, November). MANFREDI, Christopher P. (2004): "The Case for Vetting the Supremes," National Post, 3 July 2003; Patrick J. Monahan and Peter W. Hogg, "We Need an Open Parliamentary Review of Court Appointments," National Post (24 April).

MoRTon, F.L. (2006): "Judicial Appointments in Post-Charter Canada: A System in Transition," in Appointing Judges in an Age of Judicial Power: Critical Perspectives from around the World, ed. Kate Malleson and Peter H. Russell (Toronto: University of Toronto Press).

NadLer, Daniel (2006): "An Opportune Moment: The Judicial Appointment Reforms and the Judicial Credentials Demanded by the Charter", en Constitutional Forum (Núm. 15).

Nanos, Nik (2007): "Charter Values Don't Equal Canadian Values: Strong Support for Same-Sex and Property Rights," Policy Options 28, 2, February).

Neudorf, Lorne (2017): "The Supreme Court and Parliament: evolving roles and relationships", en Matthew P. Harrington, The Court and the Constitution. A 150-year retrospective (LexisNexis, Toronto).

PEACH, lan (2005): "Legitimacy on Trial: A Process for Appointing Justices to the Supreme Court of Canada", en Public Policy Paper (Num. 30, February).

Pelletier, Benoît (2016): "The Abolition of Appeals to the Judicial Committee of the Privy Council in Canada and the Evolution of the Role of the Supreme Court of Canada", en Caribbean Journal of International Relations \& Diplomacy (Vol. 4, No. 1, June).

Privy Council Office (2004): Ethics, Responsibility, Accountability: An 
Action Plan for Democratic Reform (Ottawa: Privy Council Office, February 4).

Report on 2017 Process of the Independent Advisory Board for Supreme Court of Canada Judicial Appointment, January 17, 2018.

Report of the Independent Advisory Board for Supreme Court of Canada Judicial Appointment, August-September 2016.

Ríos Álvarez, Lautaro (2002): "Generación del tribunal constitucional”, en Revista de Derecho, (Núm. 212, Vol. 1, año LXX, julio-diciembre). Russell, Peter H. (1969): The Supreme Court of Canada as a Bilingual and Bicultural Institution (Queen'Printer for Canada, Ottawa).

- (1986): "Modernizing the Supreme Court", en Gérald-A. Beaudoin (edit), The Supreme Court of Canada. Proceedings of the October 1985 Conference (Les Éditions Yvon Blais, Quebec).

- (1987): The Judiciary in Canada: The Third Branch of Government, (Mc Graw-Hill Ryerson Limited, Toronto).

- (2004): "A Parliamentary Approach to Reforming the Process of Filing vacancies on the Supreme Court of Canada", en Ottawa: Standing Committee of Justice, Human Rights, Public Safety and Emergency Preparedness.

—. (2017): "Selecting Supreme Court Justices: Is Trudeau's Sunny Way a Better Way" (University of New Brunswick Law Journal, Vol. 68, núm, 3).

Russell, Peter H.; Knopff, Rainer; Bateman, Thomas M.J. y Hiebert, Janet (2008): The Court and the Constitution: Leading Cases (Toronto: Emond Montgomery Publications Limited).

Ruíz Robledo, Agustín (1990): "Canadá, un federalismo casi olvidado", en Revista de Estudios políticos (Nueva Época), (Núm. 69, Julio-septiembre).

SAGüES, Néstor (1998): "La interpretación Judicial de la Constitución”, en Depalma (Buenos Aires).

ScheRTZER, Robert (2016): "Quebec Justices as Quebec Representatives:

National Minority Representation and the Supreme Court of Canada's Federalism Jurisprudence", en Publius: The Journal of Federalism (Vol. 46, Num. 4). 
Schratz, Paul (1997): "Public should have a say in judge selection: The bunch we've got now is a swell lot and well intentioned. Trouble is... they seem to think it's their job to right all of Canada's wrongs", en Calgary Herald (4 September).

SierRA, Luis (edit.) (2015): Diálogos constitucionales (Centro de Estudios Públicos, Santiago de Chile).

- (2016): Propuestas constitucionales. La Academia y el cambio constitucional en Chile (Centro de Estudios Públicos, Santiago de Chile) SimÓn YARZA, Fernando (2013): "La composición de la justicia constitucional en perspectiva comparada (en especial, con relación a Estados Unidos", en Teoría y Realidad Constitucional, núm. 31.

Simpson, Jeffrey (1997): "Needed: A better way to make Supreme Court appointments", en Globe and Mail (29 August)

SNELL, James G. y VAUGHAN, Frederick (1985): The supreme court of Canada. History of the Institution (University of Toronto Press, Toronto). SPEIRS, Rosemary (1997): "Filling Supreme Court vacancy fraught with peril", en The Toronto Star, 11 September 1997. "La Forest favours Us-style public review for Supreme Court judges", en Globe and Mail (3 September).

Standing Committee on Justice, Human Rights, Public Safety and Emergency Preparedness (2004), Improving the Supreme Court of Canada Appointments Process, May.

Sossin, Lorne (2013): "Should Canada have a representative Supreme Court?", en Nadia Verrelli (edit.), The democratic dilemma. Reforming Canada's Supreme Court (McGuill-Queen's University Press).

The new process for judicial appointments to the supreme court of Canada (2017), Report of the Standing Committee on Justice and Human Rights, February, 42 Parliament, 1st Session.

VerRelLI, Nadia (2013): "Reforming the SCC: Rethinking legitimacy and the appointment process", en Nadia Verrelli (edit.), The democratic dilemma. Reforming Canada's Supreme Court (McGuill-Queen's University Press), pág. 117.

Viera Álvarez, Christian; Bassa Mercado, Jaime; Ferrada Bórquez, Juan Carlos (2015): La Constitución chilena. Una revisión crítica a su prác- 
tica política, LOM.

Wayne Mackay, A.; C.M.; Q.C (2017): "The False Dichotomy Between

Regional Representation and Other Forms of Diversity: Reimagining a Representative Court", University of New Brunswick Law Journal (núm. 68 U.N.B. L.J. 46).

McwhinneY, Edward (1986): "The Supreme Court of Canada and the Constitutional Division of Powers", en Gérald-A. Beaudoin (edit), The Supreme Court of Canada. Proceedings of the October 1985 Conference (Les Éditions Yvon Blais, Quebec).

WhYTE, John D. (2016): "Political Accountability in Appointments to the Supreme Court of Canada", en Constitutional Forum constitutionnel (Special Issue: Volume 25, Number 3).

WoeHRling, José (2006): "Una introducció al sistema federal canadenc", en L'abast de l'autonomia polítiac del Quebec (Parlament de Catalunya, Barcelona).

- (2006): "Canadá. Jurisdicción", en Manuel Gerpe y Mercè Barceló (coord.), Federalismo judicial (Institut d'Estudis Autonòmics, Barcelona).

ZiEGEL, Jacob S. (2001): "Merit Selection and Democratization of Appointments to the Supreme Court of Canada," in Judicial Power and Canadian Democracy ed. Paul Howe and Peter H. Russell (Montreal: McGiII-Queen's University Press). 